\title{
A novel IncRNA MCM3AP-AS1 promotes the growth of hepatocellular carcinoma by targeting miR-194-5p/FOXA1 axis
}

Yufeng Wang ${ }^{1 \dagger}$, Liu Yang ${ }^{2 \dagger}$, Tianxiang Chen ${ }^{1 \dagger}$, Xin Liu ${ }^{3}$, Yang Guo ${ }^{4}$, Qiaojuan Zhu ${ }^{5}$, Xiangmin Tong ${ }^{2}$, Wei Yang ${ }^{1}$, Qiuran $\mathrm{Xu}^{2^{*}}$, Dongsheng Huang ${ }^{2^{*}}$ and Kangsheng $\mathrm{Tu}^{1^{*}}$ (D)

\begin{abstract}
Background: Hepatocellular carcinoma (HCC) is the most common malignant liver tumor with poor clinical outcomes. Increasing amount of long non-coding RNAs (IncRNAs) have been revealed to be implicated in the carcinogenesis and progression of HCC. However, the expressions, clinical significances, and roles of most IncRNAs in HCC are still unknown.

Methods: The expression of IncRNA MCM3AP antisense RNA 1 (MCM3AP-AS1) in HCC tissues and cell lines was detected by qRT-PCR and fluorescence in situ hybridization. Immunoblotting, CCK-8, EdU, colony formation and flow cytometry were performed to investigate the role of MCM3AP-AS1 in HCC cell proliferation, cell cycle and apoptosis in vitro. A subcutaneous tumor mouse model was constructed to analyze in vivo growth of HCC cells after MCM3AP-AS1 knockdown. The interactions among MCM3AP-AS1, miR-194-5p and FOXA1 were measured by RNA pull-down, RNA immunoprecipitation and luciferase reporter assay.
\end{abstract}

Results: We revealed a novel oncogenic IncRNA MCM3AP-AS1, which is overexpressed in HCC and positively correlated with large tumor size, high tumor grade, advanced tumor stage and poor prognosis of HCC patients. MCM3AP-AS1 knockdown suppressed HCC cell proliferation, colony formation and cell cycle progression, and induced apoptosis in vitro, and depletion of MCM3AP-AS1 inhibited tumor growth of HCC in vivo. Mechanistically, MCM3AP-AS1 directly bound to miR-194-5p and acted as competing endogenous RNA (ceRNA), and subsequently facilitated miR-194-5p's target gene forkhead box A1 (FOXA1) expression in HCC cells. Interestingly, FOXA1 restoration rescued MCM3AP-AS1 knockdown induced proliferation inhibition, G1 arrest and apoptosis of HCC cells.

Conclusions: Our results recognized MCM3AP-AS1 as a novel oncogenic IncRNA, which indicated poor clinical outcomes in patients with HCC. MCM3AP-AS1 exerted an oncogenic role in HCC via targeting miR-194-5p and subsequently promoted FOXA1 expression. Our findings suggested that MCM3AP-AS1 could be a potential prognostic biomarker and therapeutic target for HCC.

Keywords: Long non-coding RNA, Hepatocellular carcinoma, Tumorigenesis, miR-194-5p, FOXA1

\footnotetext{
*Correspondence: windway626@sina.com; dshuang@zju.edu.cn;

tks0912@foxmail.com

${ }^{+}$Yufeng Wang, Liu Yang and Tianxiang Chen contributed equally to this work.

${ }^{2}$ Key Laboratory of Tumor Molecular Diagnosis and Individualized Medicine of Zhejiang Province, Zhejiang Provincial People's Hospital (People's Hospital of Hangzhou Medical College), 158 Shangtang Road, Hangzhou 310014, Zhejiang Province, China

${ }^{1}$ Department of Hepatobiliary Surgery, the First Affiliated Hospital of Xi'an Jiaotong University, 277 Yanta West Road, Xi'an 710061, Shaanxi Province, China

Full list of author information is available at the end of the article
}

(c) The Author(s). 2019 Open Access This article is distributed under the terms of the Creative Commons Attribution 4.0 International License (http://creativecommons.org/licenses/by/4.0/), which permits unrestricted use, distribution, and reproduction in any medium, provided you give appropriate credit to the original author(s) and the source, provide a link to the Creative Commons license, and indicate if changes were made. The Creative Commons Public Domain Dedication waiver (http://creativecommons.org/publicdomain/zero/1.0/) applies to the data made available in this article, unless otherwise stated. 


\section{Background}

According to the 2018 Global Cancer Statistics, about 841,000 newly diagnosed liver cancer cases and 782,000 liver cancer deaths were appeared worldwide, with China alone accounting for about $50 \%$ of the total number of cases and deaths [1, 2]. Hepatocellular carcinoma (HCC) accounts for $75-80 \%$ of all liver cancer cases [1]. Although a significantly decreasing incidence and mortality trend for HCC was observed in China, a huge population base and rapid population growth still led to a large and rising number of new HCC cases [3]. Thus, it is worth to better understand the molecular mechanisms underlying $\mathrm{HCC}$ tumorigenesis and progression, and develop more efficient targeted therapies for HCC.

Large amount of studies report that dysregulation of oncogenes and tumor suppressor genes contribute to HCC tumorigenesis and progression, but most of them focus on protein-coding genes [4]. Only $2 \%$ of the human genome accounts for protein coding genes, while about $70 \%$ of the genome is identified as non-coding RNAs (ncRNAs) due to the great progressions of genome and transcriptome sequencing [5]. ncRNAs are further grouped into long ncRNAs (lncRNA) and small ncRNAs depending on their transcript size [6]. LncRNAs, defined as a form of ncRNAs greater than $200 \mathrm{nt}$ in length, are found to exert their gene transcription regulatory function by epigenetic regulatory mechanism [7]. Increasing evidences indicate that lncRNAs are implicated in several pathophysiological processes including human cancers [8-12]. Aberrant expression of lncRNAs has been frequently observed in cancers [1316]. Moreover, lncRNAs regulate malignant behaviors of cancer cells, such as proliferation, apoptosis resistance, migration, invasion and drug resistance [17-20]. For instance, lncRNA miR503HG expression is found to be down-regulated in HCC and represses HCC metastasis via regulating the heterogeneous nuclear ribonucleoprotein A2/B1 (HNRNPA2B1)/nuclear factor $к B(N F-\kappa B)$ signaling [21]. High expression of lncRNA linc00210 is detected in liver cancer and contributes to tumor progression by driving the activation of $\mathrm{Wnt} / \beta$-catenin pathway in a catenin beta interacting protein 1 (CT NNBIP1)-dependent manner [22]. Forkhead box A2 (FOXA2)-induced lncRNA-NEF is frequently down-regulated in HCC, and suppresses epithelial-mesenchymal transition (EMT) and tumor metastasis by antagonizing Wnt/ $\beta$-catenin pathway [23]. Moreover, lncRNA-MUF is found to be highly expressed in HCC and facilitates hepatocarcinogenesis via directly regulating Annexin A2 (ANXA2)/Wnt/ $\beta$-catenin signaling and miR-34a/Snail1/ EMT axis [24]. In our previous study, we find that lncRNA TUSC7 is down-regulated in HCC and indicates poor prognosis of patients, and it inhibits EMT and HCC metastasis by acting as miR-10a sponge and subsequently leads to Eph tyrosine kinase receptor A4 (EphA4) upregulation [25]. Furthermore, we investigate the expression and function of lncRNA CASC2 in HCC and reveal that $\mathrm{CASC} 2$ exerts an anti-metastatic role by targeting miR-367/F-box and WD repeat domain containing 7 (FBXW7) axis [26]. Although several lncRNAs have been reported to participate in the tumorigenesis and progression of $\mathrm{HCC}$, the expressions and roles of most lncRNAs in HCC are still unclear.

In this study, we analyzed differentially expressed lncRNAs in HCC compared to normal liver tissues based on the microarray data from National Center for Biotechnology Information (NCBI) Gene Expression Omnibus (GEO) dataset (GSE65485) and identified a novel highly expressed lncRNA MCM3AP antisense RNA 1 (MCM3AP-AS1) in HCC. Next, we investigated the expression, clinical significance, functional role and underlying mechanisms of MCM3AP-AS1 in HCC.

\section{Methods \\ Clinical specimens}

A total of 80 pairs of $\mathrm{HCC}$ and tumor-adjacent tissues were collected from patients who underwent hepatectomy at the First Affiliated Hospital of Xi'an Jiaotong University (Xi'an, China). None of HCC patients received any pre-operative treatments, such as radiofrequency ablation (RFA), transcatheter arterial chemoembolization (TACE), immunotherapy and targeted therapy. The tissue samples were confirmed by two histopathologists. All samples were immediately snap-frozen in liquid nitrogen and subsequently stored at $-80^{\circ} \mathrm{C}$ until RNA extraction and protein isolation. The demographic and clinicopathological features for HCC patients were described in Table 1.

\section{Cell culture}

The human immortalized normal hepatocyte cell line LO2 and HCC cell lines HepG2, Hep3B, Huh7, SMMC-7721 were maintained in our lab [26]. The cells were cultured in Dulbecco's Modified Eagle's Medium (DMEM, Gibco BRL, Grand Island, NY, USA) supplemented with $10 \%$ fetal bovine serum (Gibco) and antibiotics $(100 \mu \mathrm{g} / \mathrm{mL}$ streptomycin and $100 \mathrm{U} / \mathrm{mL}$ penicillin, Sigma, St-Louis, $\mathrm{MO}, \mathrm{USA}$ ) in a humidified incubator containing $5 \% \mathrm{CO}_{2}$ at $37^{\circ} \mathrm{C}$.

\section{Plasmids and transfection}

Two lentivector-mediated short-hairpin MCM3AP-AS1 (sh-MCM3AP-AS1-1 and sh-MCM3AP-AS1-2) and non-targeting plasmids (sh-control) were designed and synthesized by Geneseed Biotech (Guangzhou, China). Lentivirus infection of $\mathrm{HCC}$ cells was performed in the presence of Polybrene $(8 \mathrm{ng} / \mathrm{ml})$. The cDNA encoding MCM3AP-AS1 was PCR-amplified by the Thermo Scientific Phusion Flash High-Fidelity PCR Master Mix 
Table 1 Correlation between the clinicopathologic characteristics and MCMBAP-AS1 expression in hepatocellular carcinoma

\begin{tabular}{|c|c|c|c|c|c|}
\hline \multirow[t]{2}{*}{ Characteristics } & & \multirow{2}{*}{$\begin{array}{l}n \\
= \\
80\end{array}$} & \multicolumn{2}{|l|}{ MCM3AP-AS1 } & \multirow[t]{2}{*}{$P$} \\
\hline & & & Low expression $(n=40)$ & High expression $(n=40)$ & \\
\hline \multirow[t]{2}{*}{ Age (y) } & $<50$ & 33 & 14 & 19 & 0.256 \\
\hline & $\geq 50$ & 47 & 26 & 21 & \\
\hline \multirow[t]{2}{*}{ Sex } & Male & 65 & 31 & 34 & 0.390 \\
\hline & Female & 15 & 9 & 6 & \\
\hline \multirow[t]{2}{*}{ HBV } & Absent & 25 & 15 & 10 & 0.228 \\
\hline & Present & 55 & 25 & 30 & \\
\hline \multirow[t]{2}{*}{ Serum AFP level (ng/mL) } & $<20$ & 24 & 14 & 10 & 0.329 \\
\hline & $\geq 20$ & 56 & 26 & 30 & \\
\hline \multirow[t]{2}{*}{ Tumor size $(\mathrm{cm})$} & $<5$ & 30 & 21 & 9 & $0.006^{*}$ \\
\hline & $\geq 5$ & 50 & 19 & 31 & \\
\hline \multirow[t]{2}{*}{ No. of tumor nodules } & 1 & 66 & 34 & 32 & 0.556 \\
\hline & $\geq 2$ & 14 & 6 & 8 & \\
\hline \multirow[t]{2}{*}{ Cirrhosis } & Absent & 33 & 19 & 14 & 0.256 \\
\hline & Present & 47 & 21 & 26 & \\
\hline \multirow[t]{2}{*}{ Venous infiltration } & Absent & 49 & 27 & 22 & 0.251 \\
\hline & Present & 31 & 13 & 18 & \\
\hline \multirow[t]{2}{*}{ Edmondson-Steiner grading } & $1+\|$ & 60 & 34 & 26 & $0.039^{*}$ \\
\hline & $I I I+I V$ & 20 & 6 & 14 & \\
\hline \multirow[t]{2}{*}{ TNM tumor stage } & $1+\|$ & 61 & 36 & 25 & $0.004^{*}$ \\
\hline & III + IV & 19 & 4 & 15 & \\
\hline
\end{tabular}

(Thermo-Fisher Scientific, Waltham, MA, USA) and subcloned into the pcDNA3.1 plasmid (Invitrogen, Carlsbad, CA, USA). The empty plasmid pcDNA3.1 was used as negative control (EV). Hsa-miR-194-5p mimics and negative control mimics were obtained from Guangzhou RiboBio Co., Ltd. (Guangzhou, China). The plasmid expressing FOXA1 was previously described [27]. A small interfering RNA (siRNA) targeting AGO2 and scrambled siRNA were obtained from Geneseed Biotech. Plasmids were transfected into cells using Lipofectamine 2000 (Invitrogen) following the manufacturer's protocol.

\section{Quantitative real-time polymerase chain reaction (qRT- PCR)}

TRIzol reagent (Invitrogen) was used for total RNA isolation from HCC tissues and cultured cells. Total RNA was reverse transcribed into cDNA using a RevertAid First Strand cDNA Synthesis Kit (Thermo-Fisher Scientific). qRT-PCR analyses were performed using SYBR ${ }^{\bullet}$ Premix Ex Taq $^{\mathrm{Tm}}$ II (Takara, Dalian, China) and Taqman UniversalMaster Mix II (Life Technologies Corporation, Carlsbad, CA, United States) on an ABI PRISM 7300 Sequence Detection system (Applied Biosystems, Foster
City, CA, USA) in accordance with the manufacturers' instructions. The $2^{-\Delta \Delta \mathrm{Ct}}$ method was used to calculate the relative gene expression normalized by GAPDH and U6. The sequences of the primers were listed in Table 2.

\section{Western blot analysis}

HCC tissues and cells were lysed with RIPA buffer (Beyotime, Shanghai, China) and protein concentrations were quantified with a BCA protein assay kit II (BIO-RAD, Hercules, CA, USA). Protein samples were separated by $10 \%$ SDS-PAGE gel and transferred onto a nitrocellulose membrane (Invitrogen). The membranes were incubated with rabbit-anti-human FOXA1 (ab170933; Abcam, Cambridge, MA, USA), rabbit-anti-human PARP1 (ab191217; Abcam), rabbit-anti-human caspase-3 (ab32351; Abcam), rabbit-anti-human caspase-7 (ab32522; Abcam), rabbitanti-human Cyclin D1 (ab134175; Abcam), rabbit-anti-human p21 (ab109520; Abcam), mouse-anti-human $\beta$-actin (ab8226; Abcam) and mouse-anti-human GAPDH primary antibody (sc-47,724; Santa Cruz Biotechnology, Santa Cruz, Dallas, TX, USA) overnight at $4{ }^{\circ} \mathrm{C}$. Horseradish peroxidase (HRP)-conjugated secondary antibodies (NXA931-1ML and NA934-1ML, GE Healthcare Life Sciences, Beijing, China) were used to incubate the 
Table 2 Primers for qRT-PCR

\begin{tabular}{|c|c|c|}
\hline \multicolumn{2}{|l|}{ Gene name } & \multirow{2}{*}{$\begin{array}{l}\text { Primer sequences (5' to 3') } \\
\text { GCTGCTAATGGCAACACTGA }\end{array}$} \\
\hline MCM3AP-AS1 & Forward & \\
\hline & Reverse & AGGTGCTGTCTGGTGGAGAT \\
\hline \multirow[t]{2}{*}{ miR-194-5p } & Forward & CTAGTACCTAGAGGAACCTTTGAAGACTGTTACAGCTCAGCA \\
\hline & Reverse & AGCTTGCTGAGCTGTAACAGTCTTCAAAGGTTCCTCTAGGTA \\
\hline \multirow[t]{2}{*}{$\operatorname{miR}-23 \mathrm{c}$} & Forward & CCAGAAGGACGTAGAAG \\
\hline & Reverse & CTTCACTGTGATGGGCTC \\
\hline \multirow[t]{2}{*}{ TRIP12 } & Forward & CCGGGGCCCAACCACAAGAC \\
\hline & Reverse & TGGACGCTGAACGGGAACGC \\
\hline \multirow[t]{2}{*}{ CUL4B } & Forward & TGCTGCTCAGGAGGTCAGATC \\
\hline & Reverse & TGGAATCAAAGTCTTCTCTCTCGTT \\
\hline \multirow[t]{2}{*}{ FOXA1 } & Forward & GCAATACTCGCCTTACGGCT \\
\hline & Reverse & TACACACCTTGGTAGTACGCC \\
\hline \multirow[t]{2}{*}{ BTBD7 } & Forward & AGTCAAATGCCTGGTTACGG \\
\hline & Reverse & TGTCTGGCACATTGGACATT \\
\hline \multirow[t]{2}{*}{ HBEGF } & Forward & CCATTCTGAAAGGCTGGTTTG \\
\hline & Reverse & TACTCCGGAAGGGTCCTTTGT \\
\hline \multirow[t]{2}{*}{ U6 } & Forward & GTGGACCGCACAAGCTCGCT \\
\hline & Reverse & TTGTTGAACGGCACTGTGTATAGCA \\
\hline \multirow[t]{2}{*}{ GAPDH } & Forward & CAGGAGGCATTGCTGATGAT \\
\hline & Reverse & GAAGGCTGGGGCTCATTT \\
\hline
\end{tabular}

membranes for $1 \mathrm{~h}$ at room temperature. The blot signals on the membrane were visualized with ECL reagents (Millipore, Plano, TX, USA) and detected using Amersham $^{\mathrm{Ts}}$ Imager 680 from GE Healthcare Life Sciences.

\section{Cell counting Kit-8 (CCK-8) assay}

HCC cells suspensions were added to a 96-well plate at a density of $1 \times 10^{4} / \mathrm{mL}$. A total of $10 \mu \mathrm{L}$ of CCK- 8 solution (Dojindo, Tokyo, Honshu, Japan) was added to each well at the same time every day for 3 days. Finally, the absorbance at $450 \mathrm{~nm}$ was measured using a microplate reader (Thermo-Fisher Scientific) after a $2 \mathrm{~h}$ incubation.

\section{Colony formation assay}

Forty-eight hours after transfection, HCC cells $\left(1 \times 10^{3}\right.$ per well) were seeded in a 6-well plate and cultured with complete medium for 2 weeks. Cell colonies were fixed with $4 \%$ paraformaldehyde for $30 \mathrm{~min}$ and stained with $0.5 \%$ crystal violet for $30 \mathrm{~min}$ at room temperature.

\section{Ethynyl deoxyuridine (EdU) incorporation assay}

EdU incorporation assay was performed with the EdU kit (Roche, Indianapolis, IN, USA) in accordance with the manufacturer's instruction. Results were acquired using the Zeiss fluorescence photomicroscope (Carl Zeiss, Oberkochen, Germany) and quantified via counting at least five random fields.

\section{Flow cytometry assay}

For cell cycle analysis, cells were collected and fixed using $70 \%$ ethanol. After washing with PBS and subsequently washing with stain buffer, $1 \times 10^{6}$ cells were resuspended in $0.5 \mathrm{~mL}$ of PI/RNase Staining Buffer (BD biosciences, San Jose, CA, USA), and cells were incubated for $15 \mathrm{~min}$ at room temperature (RT), protected from light. A FACSCanto II flow cytometer (BD biosciences) was used to analyze cell cycle distribution. For apoptosis assay, the PE Annexin V Apoptosis Detection Kit I (BD biosciences) was used following the manufacturer's protocols. Cells were harvested and washed with pre-cold PBS buffer twice. Then, $5 \mu \mathrm{l}$ of PE Annexin V and $5 \mu \mathrm{l}$ of 7 -AAD solution were added to each sample, and cells were incubated for $15 \mathrm{~min}$ at RT. FACSCanto II flow cytometer was used to measure the cell apoptosis.

\section{Tumor xenograft model}

BALB/c nude mice (male, 4-5-week-old, 18-20 g) were obtained from Shanghai SLAC Laboratory Animal Co. Ltd. (Shanghai, China) and randomly divided into two groups ( $n=6$ per group). Hep3B cells $\left(1 \times 10^{6}\right.$ per injection) that were transfected with sh-MCM3AP-AS1 and sh-control, respectively, were implanted into the right flank of the mice via subcutaneous injection. Tumor volumes were measured every 3 days after being apparently 
observed and calculated with the following formula: Volume $=\left(\right.$ length $\times$ width $\left.^{2}\right) / 2$. After 3 weeks, all mice were sacrificed under anesthesia. Tumor tissues were harvested and subjected to immunohistochemistry for Ki-67 staining [28]. The animal experiments were approved by the Animal Care and Use Committee of Xi'an Jiaotong University.

\section{Pull-down assay with biotinylated miR-194-5p}

HepG2 cells were transfected with biotinylated wild type (wt) miR-194-5p, mutant (mt) miR-194-5p and negative control (NC) (Guangzhou RiboBio Co., Ltd). Cell lysates were harvested $48 \mathrm{~h}$ after transfection and incubated with Dynabeads M-280 Streptavidin (Invitrogen, CA, USA) for $3 \mathrm{~h}$ at $4{ }^{\circ} \mathrm{C}$ according to the manufacturer's protocol. Then, the beads were washed three times with ice-cold lysis buffer and once with high salt buffer $(0.1 \%$ SDS, $1 \%$ Triton X-100, $2 \mathrm{mM}$ EDTA, $20 \mathrm{mM}$ Tris-HCl, pH 8.0 and $500 \mathrm{mM} \mathrm{NaCl}$ ) [29]. The bound RNAs were purified using TRIzol for the qRT-PCR analysis.

\section{RNA immunoprecipitation (RIP)}

RIP assay was performed with the EZ-Magna RIP Kit (Millipore, Bedford, MA, USA) and a AGO2 antibody (Millipore) as previously described [26]. qRT-PCR was carried out to detect co-precipitated RNAs.

\section{Luciferase reporter assay}

The sequence of 3'-UTR of FOXA1 or MCM3AP-AS1 was amplified from human genomic DNA. Then these sequences were respectively subcloned into pGL3 luciferase reporter vector (Promega, Madison, WI, USA). The potential miR-194-5p binding sites were mutated by the Quick-change site-directed mutagenesis kit (Agilent Technologies, Santa Clara, CA, USA). The wt (mt) 3'-UTR of FOXA1 vector or wt (mt) MCM3AP-AS1 vector and control mimics or miR-194-5p mimics were co-transfected into HepG2 and SMMC-7721 cells. The luciferase activity was measured and normalized as previously described [26].

\section{RNA fluorescent in situ hybridization}

Cy3-labeled MCM3AP-AS1 probe were obtained from RiboBio (Guangzhou, China). Subcellular localization of MCM3AP-AS1 was detected by the FISH Kit (RiboBio, Guangzhou, China) according to the manufacturer's instructions [30].

\section{Quantitation of MCM3AP-AS1 and miR-194-5p expression levels}

The exact copy numbers of MCM3AP-AS1 and miR-194-5p transcripts per Hep3B and HepG2 cell were quantified by using quantitative real-time RT-PCR assay. In this assay, serially diluted RT-PCR products of
MCM3AP-AS1 and miR-194-5p were used as templates to formulate standard curves, and then, the exact copies of MCM3AP-AS1 and miR-194-5p per cell were calculated accordingly.

\section{Statistical analysis}

Data were analyzed using GraphPad Prism 6.0 Software (GraphPad Inc., San Diego, CA, USA). The Student's t-test was used to analyze differences between two groups, and two-way ANOVA was used when more than two groups were compared. The correlations between MCM3AP-AS1 and miR-194-5p expression were analyzed using the Pearson correlation test. Overall survival curves were protracted using the Kaplan-Meier method and estimated by the log-rank test. Differences were defined as statistically significant if $P<0.05$.

\section{Results}

A novel IncRNA MCM3AP-AS1 is overexpressed in HCC To further disclose differentially expressed lncRNAs in $\mathrm{HCC}$, we analyzed a microarray data comparing the expression of lncRNAs in $50 \mathrm{HCC}$ tissues and 5 adjacent non-tumor tissues from the GEO database with the accession number GSE65485. Thirty-seven lncRNAs were differentially expressed in HCC tissues compared to adjacent non-tumor tissues (Table 3). A novel lncRNA MCM3AP-AS1 (also known as MCM3APAS), which was 2.84-fold higher in HCC tissues than that in adjacent non-tumor tissues, caught our attention. Next, we search for the expression pattern of MCM3AP-AS1 in HCC based on TCGA data from starBase V3.0 [31]. The results showed that MCM3AP-AS1 in HCC tissues was significantly higher than that in normal liver tissues $(P<0.0001$, Additional file 1: Figure S1). Furthermore, qRT-PCR analysis of MCM3AP-AS1 in 80 pairs of HCC and matched tumor-adjacent tissues revealed that MCM3AP-AS1 was significantly overexpressed in HCC tissues compared to tumor-adjacent tissues $(\mathrm{P}<0.0001$, Fig. 1a). Elevated expression of MCM3AP-AS1 also observed in HCC cell lines (HepG2, Hep3B, SMMC-7721 and Huh7) compared to LO2 cells $(P<0.05$, Fig. 1b). Moreover, based on two other GEO datasets (GSE45436 and GSE54236) from R2: Genomics Analysis and Visualization Platform (http://r2.amc.nl), we found that MCM3AP-AS1 expression was prominently higher in HCC tissues compared to normal liver tissues $(\mathrm{P}<$ 0.0001, Fig. $1 \mathrm{c}$ and $\mathrm{d}$ ). Thus, these results indicated that MCM3AP-AS1 upregulation was a frequent event in HCC.

High level of MCM3AP-AS1 correlates with poor prognosis of HCC patients

Next, we aimed to reveal the clinical significance of MCM3AP-AS1 in HCC. TCGA data from R2: Genomics 
Table 3 Differentially expressed IncRNAs between HCC tissues and adjacent non-tumor tissues in GSE65485 dataset

\begin{tabular}{|c|c|c|c|}
\hline LncRNA & Fold change (tumor vs. normal) & $P$ value & FDR \\
\hline FAM99A & 0.04 & 0.000 & 0.010 \\
\hline LOC646982 & 0.08 & 0.001 & 0.024 \\
\hline DIO3OS & 0.16 & 0.005 & 0.061 \\
\hline PWRN1 & 0.31 & 0.010 & 0.096 \\
\hline LOC286002 & 0.43 & 0.005 & 0.061 \\
\hline NEAT1 & 0.45 & 0.009 & 0.094 \\
\hline LOC100009676 & 1.79 & 0.003 & 0.044 \\
\hline LOC440944 & 1.81 & 0.006 & 0.069 \\
\hline TUG1 & 1.83 & 0.005 & 0.061 \\
\hline LOC202781 & 1.92 & 0.001 & 0.024 \\
\hline HCG18 & 1.93 & 0.001 & 0.024 \\
\hline DGCR11 & 2.18 & 0.002 & 0.031 \\
\hline SNHG12 & 2.27 & 0.002 & 0.035 \\
\hline LOC728190 & 2.29 & 0.006 & 0.068 \\
\hline LOC100302401 & 2.33 & 0.006 & 0.068 \\
\hline SNHG10 & 2.33 & 0.003 & 0.044 \\
\hline LOC220930 & 2.34 & 0.008 & 0.088 \\
\hline LOC388796 & 2.47 & 0.000 & 0.010 \\
\hline LOC100134713 & 2.50 & 0.003 & 0.044 \\
\hline LOC100130581 & 2.55 & 0.001 & 0.024 \\
\hline LOC100128191 & 2.61 & 0.008 & 0.081 \\
\hline C6orf164 & 2.83 & 0.010 & 0.096 \\
\hline MCM3AP-AS1 & 2.84 & 0.001 & 0.024 \\
\hline SNHG1 & 2.87 & 0.000 & 0.007 \\
\hline SNHG3 & 3.08 & 0.000 & 0.015 \\
\hline LOC150381 & 3.08 & 0.005 & 0.061 \\
\hline LOC144486 & 4.35 & 0.000 & 0.010 \\
\hline LOC541471 & 5.17 & 0.001 & 0.024 \\
\hline LOC100133612 & 5.85 & 0.000 & 0.010 \\
\hline LOC92659 & 6.44 & 0.000 & 0.007 \\
\hline LOC84931 & 6.62 & 0.003 & 0.044 \\
\hline LOC284551 & 6.84 & 0.001 & 0.018 \\
\hline LOC150197 & 7.00 & 0.003 & 0.044 \\
\hline PVT1 & 7.07 & 0.000 & 0.018 \\
\hline CDKN2B-AS1 & 7.17 & 0.001 & 0.018 \\
\hline LOC286467 & 8.24 & 0.006 & 0.069 \\
\hline SNHG4 & 8.64 & 0.000 & 0.007 \\
\hline
\end{tabular}

Bold indicates interested IncRNA

Analysis and Visualization Platform (http://r2.amc.nl) revealed that MCM3AP-AS1 was more highly expressed in HCC with high tumor grades $(\mathrm{G} 3+\mathrm{G} 4)$ than that in HCC with low tumor grades $(\mathrm{G} 1+\mathrm{G} 2)(P=0.0032$, Fig. 2a). Furthermore, MCM3AP-AS1 was also more highly expressed in $\mathrm{HCC}$ with advanced tumor stages
(III-IV) than that in HCC with early tumor stages (I-II) $(P=0.0013$, Fig. $2 \mathrm{~b})$. We divided HCC patients into tow subgroups (low/high MCM3AP-AS1 level) by using the median of the cohort as a cut-off value. As shown in Table 1, the correlation analysis between MCM3AP-AS1 expression and clinicopathologic characteristics of these 80 HCC patients indicated that high expression of MCM3AP-AS1 was positively correlated with large tumor size $(P=0.006)$, high tumor grade $(P=0.039)$, and advanced TNM stages $(P=0.004)$. Kaplan-Meier survival analysis showed that HCC patients with high MCM3AP-AS1 expression had a significant poorer overall survival than those with low MCM3AP-AS1 expression $(P=0.0054$, Fig. 2c). Furthermore, TCGA data from OncoLnc (http://www.oncolnc.org/) further demonstrated that high MCM3AP-AS1 expression also indicated poor survival of HCC patients $(P=0.0112$, Fig. 2d). Collectively, our data showed that high MCM3APAS1 expression was associated with poor clinical outcomes of HCC patients.

\section{Depletion of MCM3AP-AS1 suppresses cell growth and induces apoptosis of HCC cells}

Since MCM3AP-AS1 expression was associated with tumor size, we next disclosed the biological roles of MCM3AP-AS1 in HCC cell growth. MCM3AP-AS1 were stably depleted in HepG2 and Hep3B cells with different specific shRNAs $(P<0.05$, Fig. $3 a)$. CCK- 8 assays indicated that MCM3AP-AS1 knockdown significantly inhibited the proliferation of HepG2 and Hep3B cells (P $<0.05$, Fig. $3 \mathrm{~b}$ ). Colony formation and EdU incorporation assays also indicated that MCM3AP-AS1 silencing prominently suppressed the growth of HepG2 and Hep3B cells $(P<0.05$. Figure $3 \mathrm{c}$ and $\mathrm{d})$. Moreover, flow cytometry assays revealed that the percentage of apoptotic HCC cells were obviously increased by MCM3AP-AS1 knockdown $(P<0.05$. Figure 3e). Depletion of MCM3AP-AS1 led to cell cycle arrest at G1 phase in HepG2 and Hep3B cells $(P<0.05$, Fig. 3f). Furthermore, MCM3AP-AS1 knockdown led to increased levels of cleaved PARP1, cleaved caspase-3, cleaved caspase- 7 and $\mathrm{p} 21$, and decreased Cyclin D1 expression in HCC cells $(\mathrm{P}<0.05$, Additional file 2: Figure S2). Notably, MCM3AP-AS1 knockdown did not significantly affected the growth of LO2 cells, which had low MCM3AP-AS1 expression (Additional file 3: Figure S3). Thus, these results showed that knockdown of MCM3AP-AS1 repressed the proliferation, cell cycle progression and induced apoptosis of HCC cells in vitro.

\section{MCM3AP-AS1 knockdown restrains tumorigenesis of HCC} in vivo

To further elucidate the biological roles of MCM3AP-AS1 in $\mathrm{HCC}$ tumorigenesis in vivo, Hep3B cells with 

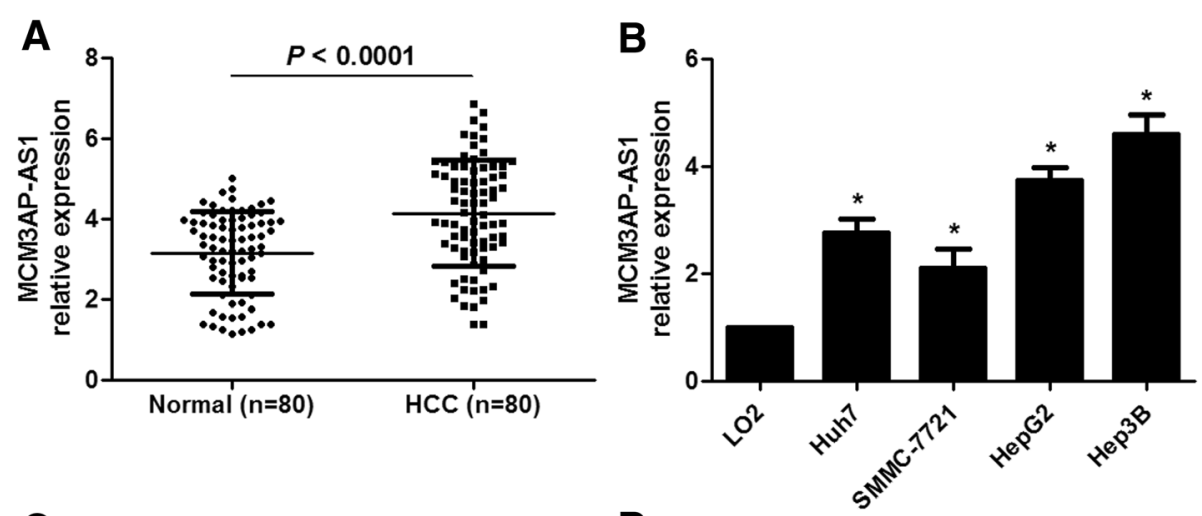

C

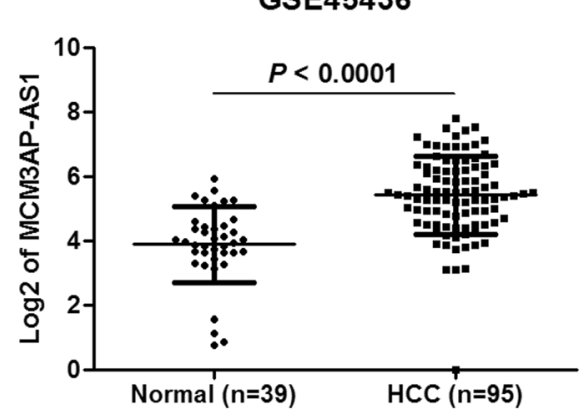

D

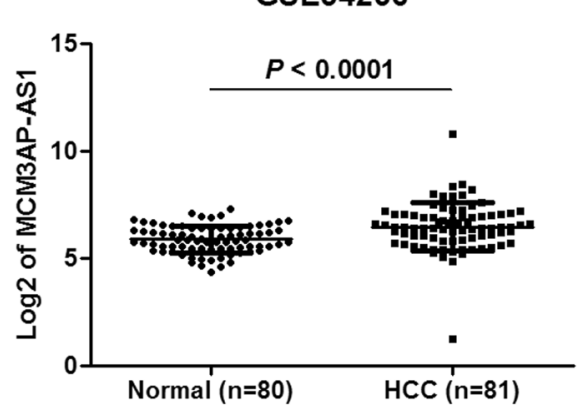

Fig. 1 MCM3AP-AS1 expression is up-regulated in HCC. a The expression of MCM3AP-AS1 in 80 pairs of HCC and matched noncancerous tissues was measured by qRT-PCR. $P<0.0001$ by Student's t-test. $\mathbf{b}$ The expressions of MCM3AP-AS1 in human normal hepatocyte cell line LO2 and HCC cell lines Huh7, SMMC-7721, HepG2 and Hep3B were detected using qRT-PCR. ${ }^{*} P<0.05$ by Student's t-test versus LO2. c and $\mathbf{d}$ Two GEO datasets (GSE45436 and GSE54236) from R2: Genomics Analysis and Visualization Platform (http://r2.amc.nl) indicated that MCM3AP-AS1 expression was prominently higher in HCC tissues compared to normal liver tissues. $P<0.0001$ by Student's t-test

MCM3AP-AS1 knockdown were implanted into nude mice via subcutaneous injection. The results of tumor growth curves and tumor weight indicated that MCM3AP-AS1 knockdown obviously reduced tumor growth in mice $(P<0.05$, Fig. $4 a$ and $b)$. Tumor tissues were harvested for qRT-PCR analysis of MCM3AP-AS1. We confirmed that lower expression of MCM3AP-AS1 was detected in tumor tissues arising from MCM3AP-AS1 knockdown group compared to control group $(P<0.05$, Fig. 4c). Ki-67 immunostaining indicated that the subcutaneous tumors formed by MCM3AP-AS1 knockdown Hep3B cells showed less Ki-67 positive cells compared to those formed by control Hep3B cells $(\mathrm{P}<$ 0.05 , Fig. 4d). Altogether, these results suggested that MCM3AP-AS1 knockdown suppressed HCC tumorigenesis in vivo.

\section{MCM3AP-AS1 acts as a molecular sponge for miR-194-5p in HCC cells}

To investigate the mechanisms underlying the role of MCM3AP-AS1 in HCC, we predicted 31 miRNAs containing binding site of MCM3AP-AS1 by using starBase V3.0. Among these miRNAs, we found that only low expression of miR-194-5p and miR-23c associated with poor prognosis of HCC patients based on TCGA data from OncoLnc $(P<0.05$, Additional file 4: Figure S4). Thus, we detected expression of miR-194-5p and miR-23c in HepG2 cells after MCM3AP-AS1 knockdown. Our data revealed that MCM3AP-AS1 knockdown significantly increased miR-194-5p expression rather than miR-23c $(P<0.05$, Fig. 5a). Consistent results were confirmed in Hep3B cells $(\mathrm{P}<0.05$, Fig. 5a). The expression of miR-194-5p in tumor tissues from MCM3AP-AS1 knockdown injected mice was significantly higher than that in control mice $(P<0.05$, Additional file 5: Figure S5A). Reduced expression of miR-194-5p was confirmed in HCC tissues compared to paracancerous tissues $(P<0.0001$, Additional file 6: Figure S6A). Analysis of TCGA data and our HCC cases indicated a significant inverse correlation between MCM3AP-AS1 and miR-194-5p expression $(P<0.05$, Additional file 6: Figure S6B and S6C). Furthermore, luciferase reporter assay revealed that miR-194-5p overexpression reduced the luciferase activity of vectors containing wt MCM3AP-AS1, but it did not influence the luciferase activity of vectors containing $\mathrm{mt}$ MCM3AP-AS1 in both SMMC-7721 and HepG2 cells $(\mathrm{P}<0.05$, Fig. $5 \mathrm{~b}$ and Additional file 7: Figure S7A). 

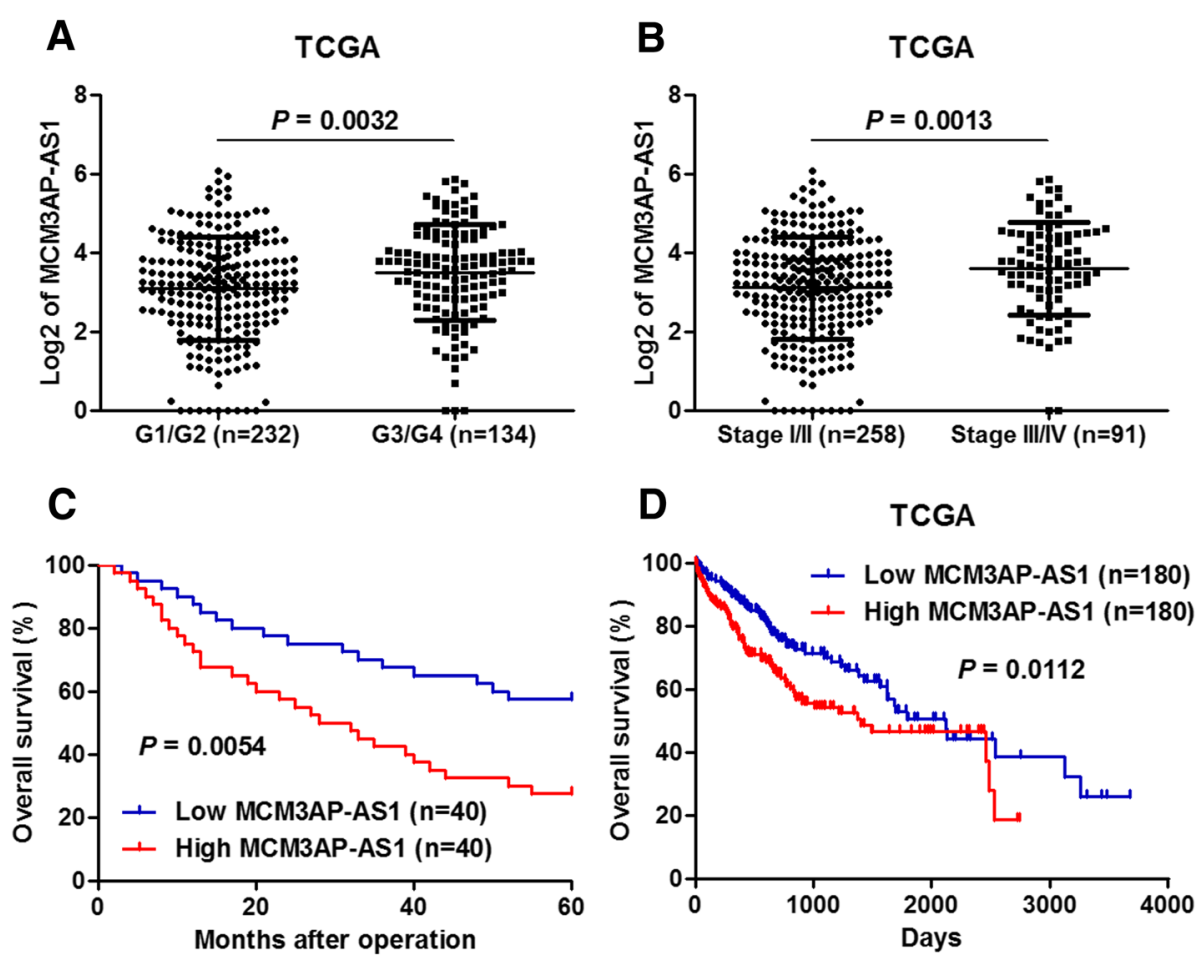

Fig. 2 The clinical significance of MCM3AP-AS1 in HCC. a Based on TCGA data from R2: Genomics Analysis and Visualization Platform (http:// r2.amc.nl), the expression of MCM3AP-AS1 in 232 cases of HCC with low tumor grades (G1-G2) and 134 samples of HCC with high tumor grades (G3-G4). $P=0.0032$ by Student's t-test. $\mathbf{b}$ The expression of MCM3AP-AS1 in 258 cases of HCC with early tumor stages (I-II) and 91 samples of HCC with advanced tumor stages (III-IV). $P=0.0013$ by Student's t-test. $\mathbf{c}$ Kaplan-Meier survival analysis revealed that HCC patients with high MCM3APAS1 expression showed a significant poorer overall survival compared to those with low MCM3AP-AS1 expression. The median expression level of MCM3AP-AS1 was used as the cut-off. $P=0.0054$ by Log-rank test. d TCGA data from OncoLnc (http://www.oncolnc.org/) further demonstrated that high MCM3AP-AS1 expression also indicated poor survival of HCC patients. The median expression level of MCM3AP-AS1 was used as the cut-off. $P=0.0112$ by Log-rank test

Notably, we found that MCM3AP-AS1 level was reduced after overexpression of miR-194-5p in HCC cells $(P<0.05$, Additional file 7: Figure S7B). Moreover, MCM3AP-AS1 was pulled down by biotin-labeled miR-194-5p, while mutagenesis of the binding sites for MCMC3AP-AS1 in miR-194-5p disrupted the interaction between MCM3AP-AS1 and miR-194-5p $(P<$ 0.05, Fig. 5c). MCM3AP-AS1 mainly located in the cytoplasm (Additional file 8: Figure S8A). qRT-PCR found that the expression level of MCM3AP-AS1 was approximately 100 copies per cell, and mature miR-194-5p levels were approximately 200 copies per cell (Additional file 8: Figure S8B), suggesting that the abundance of MCM3AP-AS1 and miR-194-5p was comparable. Thus, our data demonstrated that MCM3AP-AS1 was associated with miR-194-5p and acted as a competing endogenous RNA (ceRNA) in HCC cells. Since AGO2 is an critical component of the RNA-induced silencing complex (RISC) and acts as a key regulator of miRNA functions [32]. We conducted anti-AGO2 RIP in HepG2 cells transiently overexpressing miR-194-5p. Endogenous MCM3AP-AS1 pull-down by AGO2 was significantly enriched in miR-194-5p-transfected cells $(P<0.05$, Fig. $5 \mathrm{~d})$. In addition, AGO2 silencing impaired AGO2 dependent degradation of MCM3AP-AS1 and resulted in increased expression of MCM3AP-AS1, whereas miR-194-5p stability was reduced by AGO2 knockdown in HepG2 cells $(P<0.05$, Fig. 5 e). These data demonstrated that miR-194-5p bound to MCM3AP-AS1 and induced the degradation of MCM3AP-AS1 in HCC cells.

\section{FOXA1 is a novel target of miR-194-5p in HCC cells}

By using starBase V3.0, we found 48 candidate targets containing the complementary site for the seed region of miR-194-5p in four different prediction databases (targetScan, picTar, PITA and miRanada). Among these genes, only thyroid hormone receptor interactor 12 (TRIP12) [33], cullin 4B (CUL4B) [34], FOXA1 [27, 35, 36], BTB domain containing 7 (BTBD7) [37] and heparin binding EGF like growth factor (HBEGF) [38] were reported to be oncogenes in HCC. Then, we screened the mRNA levels of these genes after miR-194-5p overexpression in HepG2 cells. We found that miR-194-5p overexpression only reduced the 


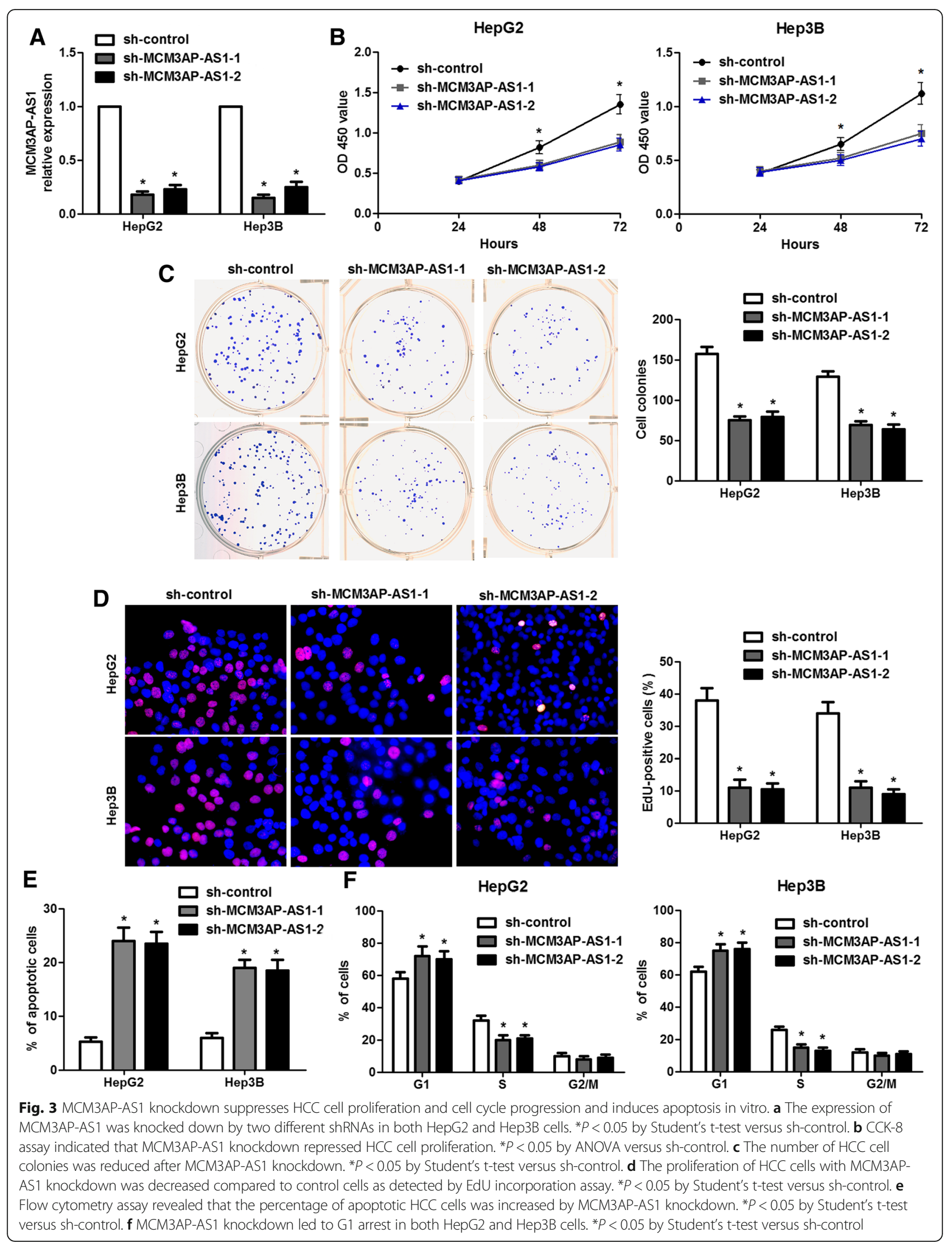



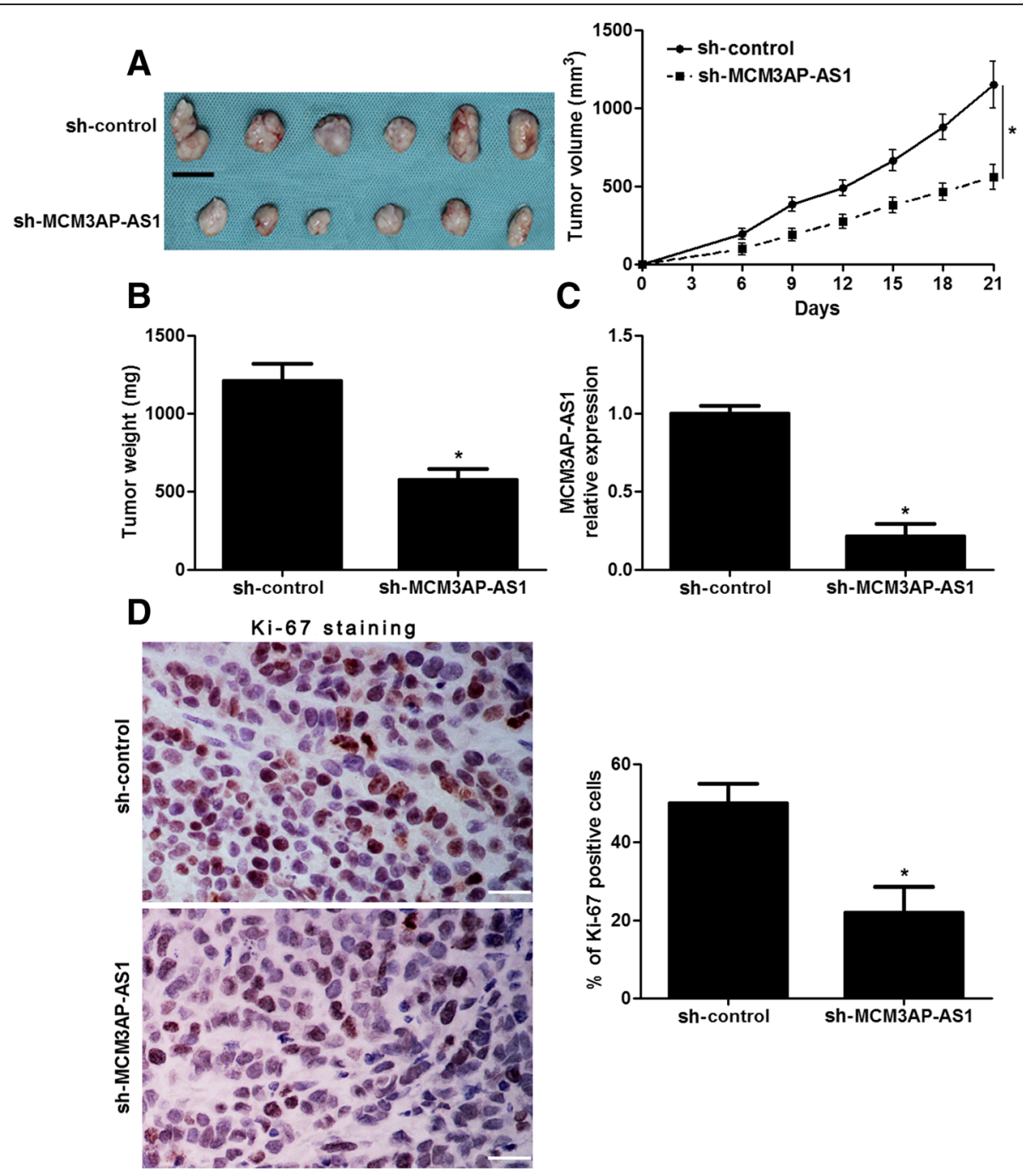

Fig. 4 MCM3AP-AS1 knockdown suppresses HCC growth in vivo. a Hep3B cells that were stably transfected with MCM3AP-AS1 shRNA ( $n=6$ ) or control shRNA $(n=6)$ were subcutaneously injected into nude mice. Tumor growth curves indicated that MCM3AP-AS1 knockdown led HCC growth restriction in mice. ${ }^{*} P<0.05$ by ANOVA. Scale bar: $1 \mathrm{~cm}$. b The subcutaneous tumors were harvested and weighted at the $21 \mathrm{st}$ day after implantation. ${ }^{*} P<0.05$ by Student's t-test. $\mathbf{c}$ Xenograft tissues were subjected to qRT-PCR for MCM3AP-AS1 expression. ${ }^{*} P<0.05$ by Student's ttest. $\mathbf{d}$ Immunostaining of Ki-67 in xenograft tissues arising from MCM3AP-AS1 knockdown group and control group. Scale bar: $50 \mu \mathrm{m}$. ${ }^{*} P<0.05$ by Student's t-test

level of FOXA1 mRNA $(P<0.05$, Fig. 6a). Furthermore, FOXA1 protein expression was significantly down-regulated by miR-194-5p in both HepG2 and Hep3B cells $(P<0.05$, Fig. 6a and b). The expression of FOXA1 protein in tumor tissues from MCM3AP -AS1 knockdown injected mice was significantly lower than that in control mice $(P<0.05$, Additional file 5 : Figure S5B). Furthermore, HCC tissues with high MCM3AP-AS1 or low miR-194-5p level showed an obvious higher level of FOXA1 protein compared to cases with low MCM3AP-AS1 or high miR-194-5p level $(P<0.05$, Additional file 6: Figure S6D and S6E). Luciferase reporter assay indicated that miR-194-5p overexpression markedly decreased the luciferase activity of vectors containing wt 3'UTR of FOXA1 rather than $\mathrm{mt}$ 3'UTR of FOXA1 $(P<0.05$, Fig. 6c). Moreover, MCM3AP-AS1 abolished the inhibitory effect of miR-194-5p on the luciferase activity of vectors containing wt 3 'UTR of FOXA1 $(P<0.05$, Fig. 6d). Meanwhile, MCM3AP-AS1 overexpression prominently increased FOXA1 expression, which was reversed by miR-194-5p restoration in SMMC-7721 cells $(P<0.05$, Fig. 6e). Overexpression of miR-194-5p obviously reduced FOXA1 level in HepG2 cells, while FOXA1 downregulation was abrogated by MCM3AP -AS1 overexpression $(\mathrm{P}<0.05$, Fig. 6f $)$. Taken 


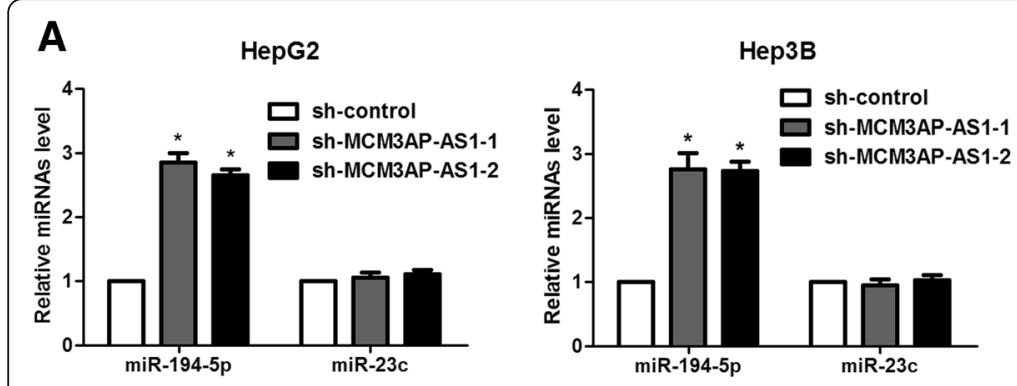

B

Wt MCM3AP-AS1 5'-tgCACCAAGAAGTTACTGTTACc-3' Has-miR-194-5p 3'-agGT-GTACCTCAACGACAATGt-5' Mt MCM3AP-AS1 5'-tgCACCAAGAAGTTACACAATCC-3'

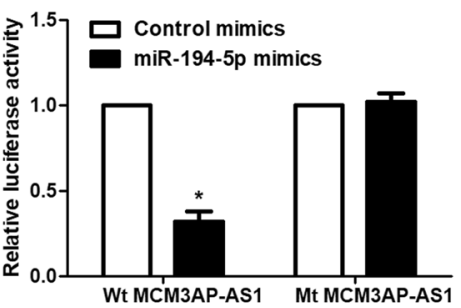

C
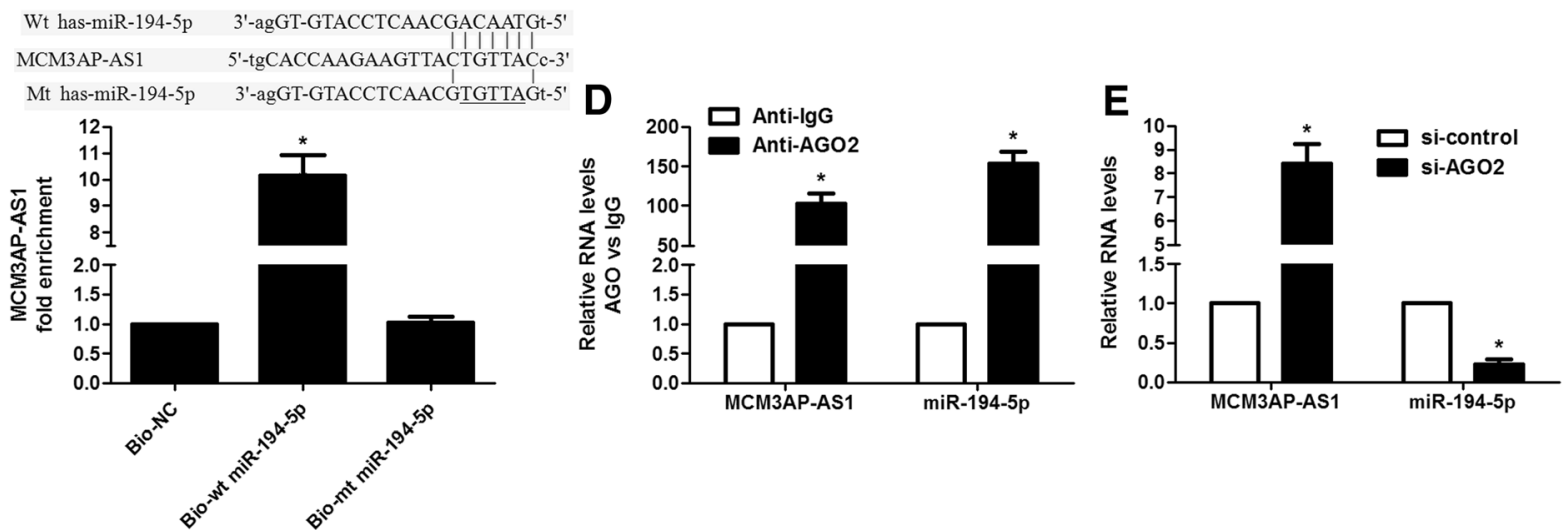

Fig. 5 MCM3AP-AS1 functions as molecular sponge for miR-194-5p in HCC cells. a HepG2 and Hep3B cells that were transfected with two different MCM3AP-AS1 shRNAs and control shRNA, respectively, were subjected to qRT-PCR for miRNAs expression. ${ }^{*} P<0.05$ by Student's t-test versus sh-control. (b) Complementary sequence between miR-194-5p and wild type (wt) MCM3AP-AS1. The putative binding sites of miR-194-5p was mutated in MCM3AP-AS1 (mt MCM3AP-AS1). SMMC-7721 cells that were co-transfected with miR-194-5p mimics and wt or mt MCM3AP-AS1 vector were measured for luciferase activity. ${ }^{*} P<0.05$ by Student's t-test. c The sequences for wt and mt forms of miR-194-5p were shown. MCM3AP-AS1 was highly enriched in the sample pulled down by biotinylated wt miR-194-5p rather than mt miR-194-5p. *P<0.05 by Student's ttest versus Bio-NC. $\mathbf{d}$ Anti-AGO2 RIP was performed in HepG2 cells transiently overexpressing miR-194-5p. The results indicted that MCM3AP-AS1, miR-194-5p and AGO2 formed a complex in miR-194-5p-transfected HepG2 cells. ${ }^{*} P<0.05$ by Student's t-test. e HepG2 cells that were transfected with AGO2 siRNA or control siRNA were subjected to qRT-PCR for MCM3AP-AS1 and miR-194-5p expression. ${ }^{*} P<0.05$ by Student's t-test

together, MCM3AP-AS1 functioned as a ceRNA to promote FOXA1 expression by sponging miR-194-5p in HCC.

\section{FOXA1 restoration attenuates the effect of MCM3AP-AS1 knockdown on HCC cells}

To explore whether the FOXA1 was critical for cell proliferation restriction, G1 arrest and apoptosis upon MCM3AP-AS1 knockdown, HepG2 cells with MCM 3AP-AS1 knockdown were transfected with FOXA1 expression vectors. CCK8 assays indicated that restoration of FOXA1 attenuated the proliferation suppressive role of MCM3AP-AS1 knockdown in HepG2 cells $(P<$ 0.05 , Fig. 7a). Flow cytometry assays revealed that FOXA1 restoration reversed apoptosis and G1 arrest in HepG2 cells with MCM3AP-AS1 knockdown $(\mathrm{P}<0.05$, Fig. $7 \mathrm{~b}$ and c). Moreover, colony formation and EdU incorporation assays also indicated that overexpression of FOXA1 attenuated the growth arrest of HepG2 cells induced by MCM3AP-AS1 knockdown $(\mathrm{P}<0.05$, Fig. 7d and e). Thus, these results strongly suggested that MCM3PA-AS1 knockdown induced cell proliferation restriction, cell cycle arrest and apoptosis was at least partially mediated by FOXA1 inhibition in HCC.

\section{Discussion}

Tens of thousands lncRNAs are identified by human transcriptome sequencing. Increasing studies have revealed more and more cancer-related lnRNAs, some of them play essential roles in tumorigenesis and progression of HCC [39]. Beside the well characterized lncRNAs, it is still worth to investigate potential essential lncRNAs in controlling HCC initiation and progression. Thus, we re-analyzed the microarray data from public available database about the differentially exp ressed lncRNAs in HCC. Interestingly, we found a novel IncRNA MCM3AP-AS1, which was markedly overexpressed in HCC tissues and cell lines compared with 


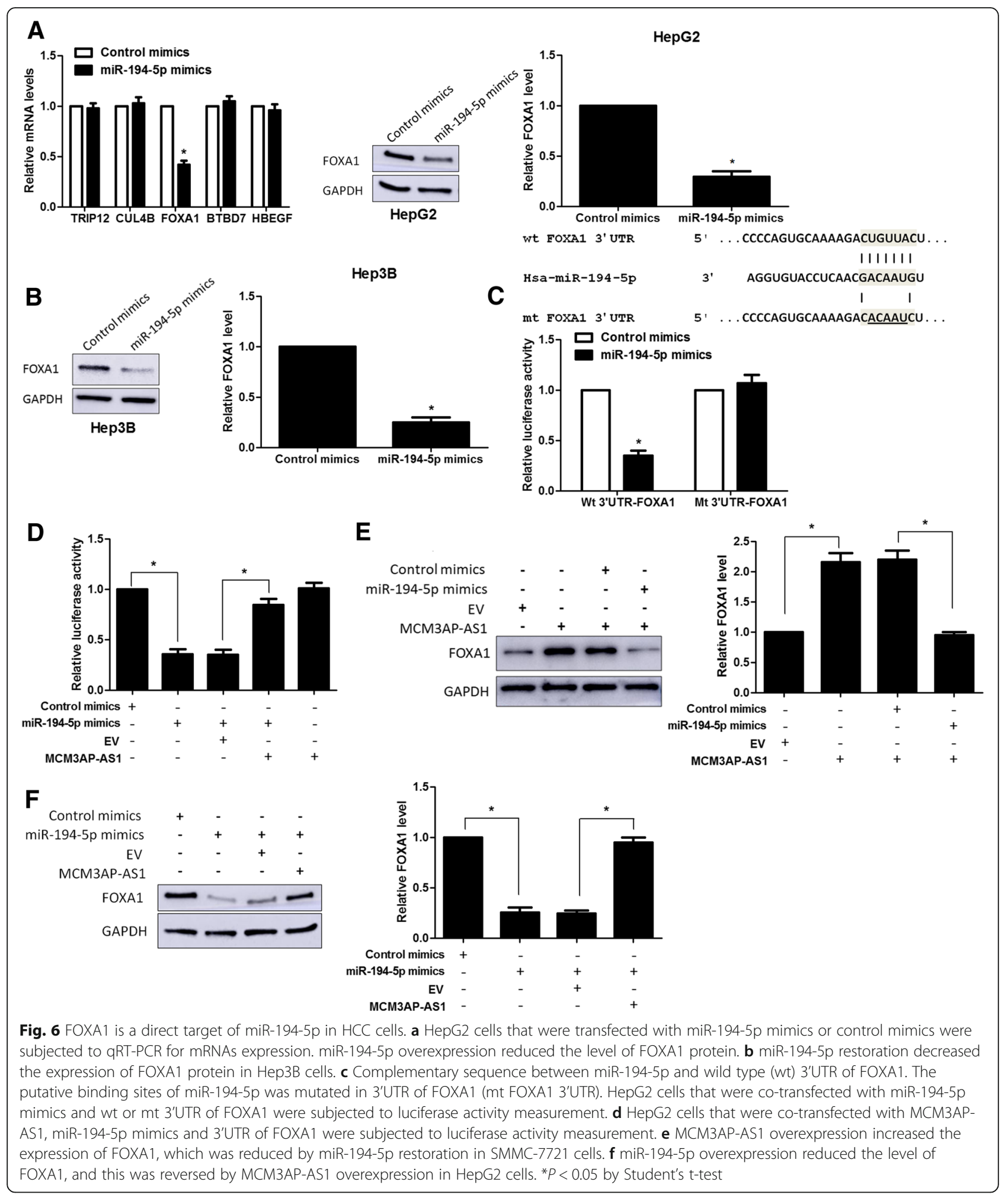

tumor-adjacent tissues and normal hepatic cell line, respectively. High expression of MCM3AP-AS1 was positively associated with large tumor size, high tumor grade and advanced tumor stage. Moreover, elevated expression of MCM3AP-AS1 indicated poor clinical outcomes of HCC patients. Therefore, our study identified a novel HCC-related lncRNA MCM3AP-AS1, which predicted poor prognosis of HCC patents. A recent study also reports that MCM3AP-AS1 functions as an oncogenic lncRNA and it is overexpressed in glioma-associated 


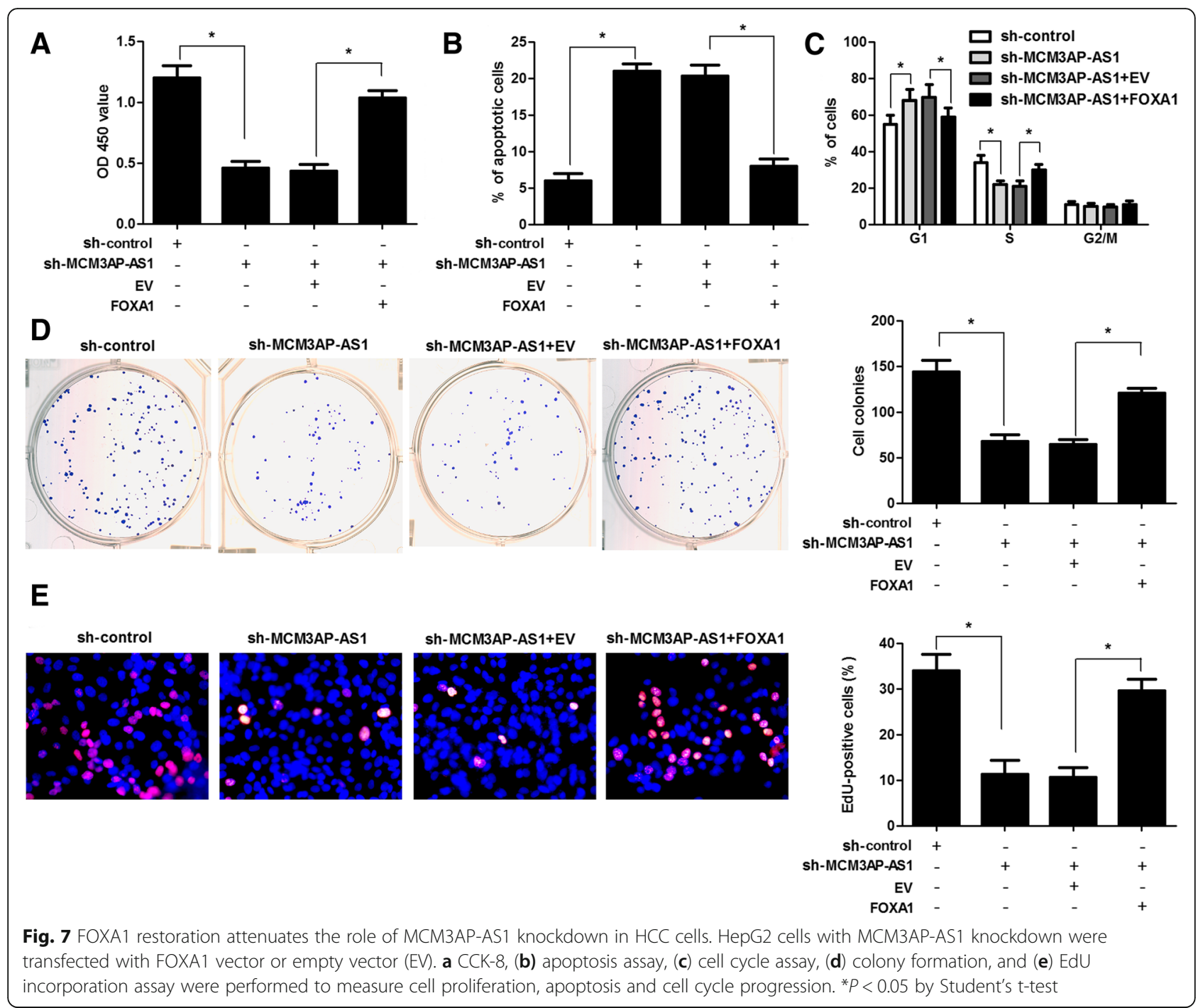

endothelial cells (GECs) [40]. TCGA data from OncoLnc also reveals that high expression of MCM3AP-AS1 indicates poor survival of patients with colon adenocarcinoma. Thus, the aberrant expression and clinical significance of MCM3AP-AS1 in other human cancers are worth to be investigated.

Next, loss-of-function assays indicated that MCM3APAS1 knockdown inhibited cell proliferation, colony formation and cell cycle progression, and induced apoptosis of HCC cells in vitro. In vivo experiments found that MCM3AP-AS1 silencing suppressed HCC tumor growth in mice. Taken together, these results suggested an oncogenic role of MCM3AP-AS1 in HCC. MCM3AP-AS1 promotes angiogenesis of glioblastoma in vitro [40]. This implies that MCM3AP-AS1 may regulate other malignant behaviors of HCC cells including metastasis and angiogenesis, which needs further study.

One of the most popular functional model for lncRNAs is that lncRNAs function as ceRNAs to sponge
miRNAs via sequence complementarity and subsequently influence functional roles of miRNAs [39]. Yang et al. find that MCM3AP-AS1 acts as a ceRNA to promote KLF5/AGGF1 axis, and activate PI3K/AKT and ERK1/2 signaling pathways by sponging miR-211 in glioblastoma [40]. Here, we found that MCM3AP-AS1 mainly located in the cytoplasm and the abundance of MCM3AP-AS1 was comparable to that of miR-194-5p in HCC cells. Moreover, MCM3AP-AS1 silencing prominently up-regulated miR-194-5p expression in HCC cells. An inverse correlation between MCM3AP-AS1 and miR-194-5p expression was confirmed in HCC tissues from our cohort and TCGA database. The following luciferase reporter assay and RNA pull down assay demonstrated that MCM3AP-AS1 acted as molecular sponge for miR-194-5p by directly binding to complementary sequence in HCC cells. Since miR-194-5p suppresses cell proliferation and blocks G1-S transition in HCC cells [41]. And a recent study also reports the 
lncRNA XIST regulation of miR-194-5p in HCC [42]. Thus, we considered that MCM3AP-AS1 played an oncogenic role in HCC via down-regulating miR-194-5p expression. FOXA1, a transcription factor, promotes tumor growth of HCC [27, 35,36]. Our previous study shows that FOXA1 mediates the tumor suppressive role of miR-212 in HCC tumor growth [27]. MSL2 contributes to the growth of $\mathrm{HCC}$ cells in vitro and in vivo and is up-regulated $\mathrm{HBx}$-mediated activation of YAP/FOXA1 signaling [35]. Moreover, tumor suppressive IncRNA MT1DP inhibits cell proliferation and colony formation, but induces apoptosis of HCC cell in a FOXA1 depen dent manner [36]. In this study, FOXA1 was identified as a direct target of miR-194-5p in HCC cells. miR-194-5p regulation of FOXA1 is also observed in lung cancer [43]. Notably, MCM3AP-AS1 positively regulated FOXA1 abundance in HCC cells, while miR-194-5p showed an opposite regulatory effect. A positive correlation between MCM3AP-AS1 and FOXA1 and a negative correlation between miR-194-5p and FOXA1 were observed in HCC tissues. Importantly, FOXA1 restoration reversed MCM3AP-AS1 knockdown induced HCC cell proliferation restriction, cell cycle arrest and apoptosis. To conclude, our study provided a novel insight that MCM3AP-AS1/miR-194-5p/FOXA1 axis contributed to the growth of HCC. MCM3AP-AS1/ miR-194-5p/FOXA1 axis might be potential therapeutic targets for HCC.

\section{Conclusions}

In summary, our findings identified a novel lncRNA MCM3AP-AS1, which was up-regulated in HCC and associated with poor prognosis of HCC patients. MCM3AP-AS1 knockdown inhibited the proliferation, cell cycle progression and induced apoptosis of HCC cells, and suppressed tumor growth of HCC in vivo. Mechanistically, MCM3AP-AS1 functioned as an oncogenic lncRNA by acting as a ceRNA to sponge miR-194-5p and subsequently promoted FOXA1 expression. Our data suggested that MCM3AP-AS1 might be a potential prognostic biomarker and therapeutic target for HCC.

\section{Additional files}

Additional file 1: Figure S1. The expression of MCM3AP-AS1 between HCC and normal liver tissues in TCGA database. The levels of MCM3APAS1 in HCC tissues were obviously higher than that in normal liver tissues in TCGA database from starBase V3.0 platform. $P<0.0001$ by Student's ttest. (TIF $198 \mathrm{~kb}$ )

Additional file 2: Figure S2. MCM3AP-AS1 knockdown induced apoptosis of HCC cells. MCMBAP-AS1 knockdown increased the levels of cleaved PARP1, cleaved caspase-3, cleaved caspase-7 and p21, and reduced the expression of Cyclin D1 in HepG2 and Hep3B cells. ${ }^{*} P<0.05$ by Student's t-test versus sh-control. (TIF $304 \mathrm{~kb}$ )
Additional file 3: Figure S3. MCM3AP-AS1 knockdown did not impact the growth of LO2 cells. LO2 cells were transfected with MCM3AP-AS1 shRNAs and control shRNA. (A) CCK-8, (B) colony formation, (C) EdU incorporation assay, (D) apoptosis assay, and (E) cell cycle assay were performed to measure cell proliferation, apoptosis and cell cycle progression. (TIF $104 \mathrm{~kb}$ )

Additional file 4: Figure S4. The prognostic significance of miR-194-5p and miR-23c in HCC based on TCGA database. Kaplan-Meier survival analysis revealed that HCC patients with low miR-194-5p (miR-23c) expression showed a significant poorer overall survival compared to those with high miR-194-5p (miR-23c) expression based on TCGA data from

OncoLnc platform. $P=0.00808$ and 0.00319 by Log-rank test. (TIF $137 \mathrm{~kb}$ )

Additional file 5: Figure S5. The expression of miR-194-5p and FOXA1 in xenograft tissues. Xenograft tissues arising from MCM3AP-AS1 knockdown group $(n=6)$ and control group $(n=6)$ were subjected to qRT-PCR and immunoblotting for (A) miR-194-5p and (B) FOXA1 protein expression, respectively. ${ }^{*} P<0.05$ by Student's t-test. (TIF $169 \mathrm{~kb}$ )

Additional file 6: Figure S6. The relationships among MCM3AP-AS1, miR-194-5p and FOXA1 expression in HCC. (A) The expression of miR194-5p in HCC tissues $(n=80)$ was markedly lower than that in paracancerous tissues $(n=80)$. $P<0.0001$ by Student's t-test. (B) A negative correlation between MCM3AP-AS1 and miR-194-5p expression was observed in 80 cases of HCC tissues. $r=-0.2489, P=0.0260$ by Spearman correlation test. (C) MCM3AP-AS1 was inversely correlated with miR-194-5p expression in HCC tissues based on TCGA database from starBase V3.0 platform. $r=-0.159, P=0.00222$ by Spearman correlation test. (D) Immunoblotting analysis revealed that the expression of FOXA1 protein in HCC tissues with high MCM3AP-AS1 level $(n=40)$ was significantly higher than that in HCC tissues with low MCM3AP-AS1 level $(n=40)$. ${ }^{*} P<0.05$ by Student's t-test. (E) Immunoblotting analysis revealed that the expression of FOXA1 protein in HCC tissues with low miR-194-5p level $(n=40)$ was significantly higher than that in HCC tissues with high miR-194-5p level $(n=40)$. ${ }^{*} P<0.05$ by Student's t-test. (TIF $522 \mathrm{~kb}$ )

Additional file 7: Figure S7. miR-194-5p inversely regulates MCM3APAS1 expression in HCC cells. (A) HepG2 cells that were co-transfected with miR-194-5p mimics and wt or mt MCM3AP-AS1 vector were measured for luciferase activity. (B) miR-194-5p overexpression obviously reduced the expression of MCM3AP-AS1 in HepG2 and Hep3B cells. *P < 0.05 by Student's t-test. (TIF $54 \mathrm{~kb}$ )

Additional file $\mathbf{8}$ Figure S8. The subcellular location and copy number of MCM3AP-AS1 in HCC cells. (A) RNA fluorescent in situ hybridization indicated MCM3AP-AS1 mainly located in cytoplasm of Hep3B and HepG2 cells. (B) QRT-PCR was performed to measure the copy numbers of MCM3AP-AS1 and miR-194-5p in HepG2 and Hep3B cells. (TIF 679 kb)

\section{Abbreviations}

ANXA2: Annexin A2; BTBD7: BTB domain containing 7; ceRNA: Competing endogenous RNA; CTNNBIP1: Catenin beta interacting protein 1;

CUL4B: Cullin 4B; EMT: Epithelial-mesenchymal transition; EphA4: Eph tyrosine kinase receptor A4; FBXW7: F-box and WD repeat domain containing 7; FOXA2: Forkhead box A2; GECs: Glioma-associated endothelial cells; GEO: Gene Expression Omnibus; HBEGF: Heparin binding EGF like growth factor; HCC: Hepatocellular carcinoma; HNRNPA2B1: Heterogeneous nuclear ribonucleoprotein A2/B1; MCM3AP-AS1: MCM3AP antisense RNA 1; NCBI: National Center for Biotechnology Information; ncRNAs: Non-coding RNAs; NF-kB: Nuclear factor KB; RFA: Radiofrequency ablation; TACE: Transcatheter arterial chemoembolization; TRIP12: Thyroid hormone receptor interactor 12

\section{Acknowledgements}

Not applicable.

\section{Funding}

This study was supported by grants from the Co-construction of Provincial and Department Project (WKJ-ZJ-1919); the National Natural Science Foundation of China (81773123, 81874049, 81602179, 81502092); the Zhejiang Provincial Natural Science Foundation of China (LY16H160043); the General Project Funds from the Health Department of Zhejiang Province (2016KYA022, 2015KYB033). 


\section{Availability of data and materials}

All data generated or analyzed during this study are included either in this article or in the supplementary information files.

\section{Authors' contributions}

$\mathrm{QX}, \mathrm{DH}, \mathrm{WY}$ and $\mathrm{KT}$ conceived and designed the experiments; QX, YW, XL, $L Y, T C$ and $Y G$ performed the experiments; $Q X, L Y, T C$ and $Y W$ analyzed the data; QZ and XT contributed reagents/materials/analysis tools; QX and KT wrote the paper. All authors read and approved the final manuscript.

\section{Ethics approval and consent to participate}

All procedures performed in studies involving human participants were in accordance with the ethical standards of the Research Ethics Committee of The First Affiliated Hospital of Xi'an Jiaotong University and with the 1964 Helsinki declaration and its later amendments. ALL written informed consent to participate in the study was obtained from HCC patients for samples to be collected from them.

\section{Consent for publication}

Not applicable.

\section{Competing interests}

The authors declare that they have no competing interests.

\section{Publisher's Note}

Springer Nature remains neutral with regard to jurisdictional claims in published maps and institutional affiliations.

\section{Author details}

${ }^{1}$ Department of Hepatobiliary Surgery, the First Affiliated Hospital of Xi'an Jiaotong University, 277 Yanta West Road, Xi'an 710061, Shaanxi Province, China. ${ }^{2}$ Key Laboratory of Tumor Molecular Diagnosis and Individualized Medicine of Zhejiang Province, Zhejiang Provincial People's Hospital (People's Hospital of Hangzhou Medical College), 158 Shangtang Road, Hangzhou 310014, Zhejiang Province, China. ' ${ }^{3}$ Department of Neurosurgery, Zhejiang Provincial People's Hospital (People's Hospital of Hangzhou Medical College), 158 Shangtang Road, Hangzhou 310014, Zhejiang Province, China. ${ }^{4}$ BengBu Medical College, Bengbu 233030, Anhui Province, China. ${ }^{5}$ Department of Second Clinical Medical College, Zhejiang Chinese Medical University, Hangzhou 310000, Zhejiang Province, China.

Received: 3 June 2018 Accepted: 13 February 2019 Published online: 19 February 2019

\section{References}

1. Bray F, Ferlay J, Soerjomataram I, Siegel RL, Torre LA, Jemal A. Global cancer statistics 2018: GLOBOCAN estimates of incidence and mortality worldwide for 36 cancers in 185 countries. CA Cancer J Clin. 2018;68(6):394-424.

2. Chen W, Zheng R, Baade PD, Zhang S, Zeng H, Bray F, Jemal A, Yu XQ, He J. Cancer statistics in China, 2015. CA Cancer J Clin. 2016;66(2):115-32.

3. Omata M, Cheng AL, Kokudo N, Kudo M, Lee JM, Jia J, Tateishi R, Han KH, Chawla YK, Shiina S, et al. Asia-Pacific clinical practice guidelines on the management of hepatocellular carcinoma: a 2017 update. Hepatol Int. 2017; 11(4):317-70.

4. Hemminki K, Hemminki A, Forsti A, Sundquist K, Li X. Genetics of gallbladder cancer. Lancet Oncol. 2017;18(6):e296.

5. Yan X, Hu Z, Feng Y, Hu X, Yuan J, Zhao SD, Zhang Y, Yang L, Shan W, He $\mathrm{Q}$, et al. Comprehensive genomic characterization of long non-coding RNAs across human cancers. Cancer Cell. 2015;28(4):529-40.

6. Batista PJ, Chang HY. Long noncoding RNAs: cellular address codes in development and disease. Cell. 2013;152(6):1298-307.

7. Ponting $\mathrm{CP}$, Oliver PL, Reik W. Evolution and functions of long noncoding RNAs. Cell. 2009;136(4):629-41.

8. Schmitt AM, Chang HY. Long noncoding RNAs in Cancer pathways. Cancer Cell. 2016;29(4):452-63.

9. Leucci E, Vendramin R, Spinazzi M, Laurette P, Fiers M, Wouters J, Radaelli E, Eyckerman S, Leonelli C, Vanderheyden $\mathrm{K}$, et al. Melanoma addiction to the long non-coding RNA SAMMSON. Nature. 2016;531(7595):518-22.

10. Yuan JH, Liu XN, Wang TT, Pan W, Tao QF, Zhou WP, Wang F, Sun SH. The MBNL3 splicing factor promotes hepatocellular carcinoma by increasing
PXN expression through the alternative splicing of IncRNA-PXN-AS1. Nat Cell Biol. 2017;19(7):820-32.

11. Xu D, Yang F, Yuan JH, Zhang L, Bi HS, Zhou CC, Liu F, Wang F, Sun SH. Long noncoding RNAs associated with liver regeneration 1 accelerates hepatocyte proliferation during liver regeneration by activating Wnt/betacatenin signaling. Hepatology. 2013;58(2):739-51.

12. Zhang C, Yuan J, Hu H, Chen W, Liu M, Zhang J, Sun S, Guo Z. Long noncoding RNA CHCHD4P4 promotes epithelial-mesenchymal transition and inhibits cell proliferation in calcium oxalate-induced kidney damage. Braz J Med Biol Res. 2017;51(1):e6536.

13. Lin $A$, Hu Q, Li C, Xing Z, Ma G, Wang C, Li J, Ye Y, Yao J, Liang K, et al. The LINK-A IncRNA interacts with PtdIns( $(3,4,5) P 3$ to hyperactivate AKT and confer resistance to AKT inhibitors. Nat Cell Biol. 2017;19(3):238-51.

14. Grelet S, Link LA, Howley B, Obellianne C, Palanisamy V, Gangaraju VK, Diehl $J A$, Howe PH. A regulated PNUTS mRNA to IncRNA splice switch mediates EMT and tumour progression. Nat Cell Biol. 2017;19(9):1105-15.

15. Reis EM, Verjovski-Almeida S. Perspectives of long non-coding RNAs in Cancer diagnostics. Front Genet. 2012;3:32.

16. Zhang L, Yang F, Yuan JH, Yuan SX, Zhou WP, Huo XS, Xu D, Bi HS, Wang F, Sun SH. Epigenetic activation of the MiR-200 family contributes to H19mediated metastasis suppression in hepatocellular carcinoma. Carcinogenesis. 2013;34(3):577-86.

17. Zhu XT, Yuan JH, Zhu TT, Li YY, Cheng XY. Long noncoding RNA glypican 3 (GPC3) antisense transcript 1 promotes hepatocellular carcinoma progression via epigenetically activating GPC3. FEBS J. 2016;283(20):3739-54.

18. Deng L, Yang SB, Xu FF, Zhang JH. Long noncoding RNA CCAT1 promotes hepatocellular carcinoma progression by functioning as let-7 sponge. J Exp Clin Cancer Res. 2015;34:18.

19. Lin A, Li C, Xing Z, Hu Q, Liang K, Han L, Wang C, Hawke DH, Wang S, Zhang Y, et al. The LINK-A IncRNA activates normoxic HIF1alpha signalling in triple-negative breast cancer. Nat Cell Biol. 2016;18(2):213-24.

20. Li JK, Chen C, Liu JY, Shi JZ, Liu SP, Liu B, Wu DS, Fang ZY, Bao Y, Jiang MM, et al. Long noncoding RNA MRCCAT1 promotes metastasis of clear cell renal cell carcinoma via inhibiting NPR3 and activating p38-MAPK signaling. Mol Cancer. 2017;16(1):111.

21. Wang H, Liang L, Dong Q, Huan L, He J, Li B, Yang C, Jin H, Wei L, Yu C, et al. Long noncoding RNA miR503HG, a prognostic indicator, inhibits tumor metastasis by regulating the HNRNPA2B1/NF-kappaB pathway in hepatocellular carcinoma. Theranostics. 2018;8(10):2814-29.

22. Fu X, Zhu X, Qin F, Zhang Y, Lin J, Ding Y, Yang Z, Shang Y, Wang L, Zhang $Q$, et al. Linc00210 drives Wnt/beta-catenin signaling activation and liver tumor progression through CTNNBIP1-dependent manner. Mol Cancer. 2018;17(1):73.

23. Liang WC, Ren JL, Wong CW, Chan SO, Waye MM, Fu WM, Zhang JF. LncRNA-NEF antagonized epithelial to mesenchymal transition and cancer metastasis via cis-regulating FOXA2 and inactivating Wnt/beta-catenin signaling. Oncogene. 2018;37(11):1445-56.

24. Yan X, Zhang D, Wu W, Wu S, Qian J, Hao Y, Yan F, Zhu P, Wu J, Huang G, et al. Mesenchymal stem cells promote Hepatocarcinogenesis via IncRNAMUF interaction with ANXA2 and miR-34a. Cancer Res. 2017;77(23):6704-16.

25. Wang Y, Liu Z, Yao B, Dou C, Xu M, Xue Y, Ding L, Jia Y, Zhang H, Li $\mathrm{Q}$, et al. Long non-coding RNA TUSC7 acts a molecular sponge for miR-10a and suppresses EMT in hepatocellular carcinoma. Tumour Biol. 2016;37(8):11429-41.

26. Wang Y, Liu Z, Yao B, Li Q, Wang L, Wang C, Dou C, Xu M, Liu Q, Tu K. long non-coding RNA CASC2 suppresses epithelial-mesenchymal transition of hepatocellular carcinoma cells through CASC2/miR-367/FBXW7 axis. Mol Cancer. 2017;16(1):123.

27. Dou C, Wang Y, Li C, Liu Z, Jia Y, Li Q, Yang W, Yao Y, Liu Q, Tu K. MicroRNA-212 suppresses tumor growth of human hepatocellular carcinoma by targeting FOXA1. Oncotarget. 2015;6(15):13216-28.

28. Xu Q, Tu J, Dou C, Zhang J, Yang L, Liu X, Lei K, Liu Z, Wang Y, Li L, et al. HSP90 promotes cell glycolysis, proliferation and inhibits apoptosis by regulating PKM2 abundance via Thr-328 phosphorylation in hepatocellular carcinoma. Mol Cancer. 2017;16(1):178.

29. Wang SH, Zhang WJ, Wu XC, Weng MZ, Zhang MD, Cai Q, Zhou D, Wang $J D$, Quan ZW. The IncRNA MALAT1 functions as a competing endogenous RNA to regulate MCL-1 expression by sponging miR-363-3p in gallbladder cancer. J Cell Mol Med. 2016;20(12):2299-308.

30. Wang Y, Sun L, Wang L, Liu Z, Li Q, Yao B, Wang C, Chen T, Tu K, Liu Q. Long non-coding RNA DSCR8 acts as a molecular sponge for miR-485-5p to 
activate Wnt/beta-catenin signal pathway in hepatocellular carcinoma. Cell Death Dis. 2018;9(9):851.

31. Li JH, Liu S, Zhou H, Qu LH, Yang JH. starBase v2.0: decoding miRNA-ceRNA, miRNA-ncRNA and protein-RNA interaction networks from large-scale CLIPSeq data. Nucleic Acids Res. 2014;42(Database issue):D92-7.

32. Ye Z, Jin H, Qian Q. Argonaute 2: a novel rising star in Cancer research. J Cancer. 2015;6(9):877-82

33. Cai JB, Shi GM, Dong ZR, Ke AW, Ma HH, Gao Q, Shen ZZ, Huang XY, Chen $\mathrm{H}$, Yu DD, et al. Ubiquitin-specific protease 7 accelerates p14(ARF) degradation by deubiquitinating thyroid hormone receptor-interacting protein 12 and promotes hepatocellular carcinoma progression. Hepatology. 2015;61(5):1603-14.

34. Yuan J, Han B, Hu H, Qian Y, Liu Z, Wei Z, Liang X, Jiang B, Shao C, Gong Y. CULAB activates Wnt/beta-catenin signalling in hepatocellular carcinoma by repressing Wht antagonists. J Pathol. 2015;235(5):784-95.

35. Gao Y, Feng J, Yang G, Zhang S, Liu Y, Bu Y, Sun M, Zhao M, Chen F, Zhang W, et al. Hepatitis B virus $X$ protein-elevated MSL2 modulates hepatitis B virus covalently closed circular DNA by inducing degradation of APOBEC3B to enhance hepatocarcinogenesis. Hepatology. 2017;66(5):1413-29.

36. Yu W, Qiao Y, Tang X, Ma L, Wang Y, Zhang X, Weng W, Pan Q, Yu Y, Sun F, et al. Tumor suppressor long non-coding RNA, MT1DP is negatively regulated by YAP and Runx2 to inhibit FoxA1 in liver cancer cells. Cell Signal. 2014;26(12):2961-8.

37. Tao YM, Huang JL, Zeng S, Zhang S, Fan XG, Wang ZM, Yang HX, Yuan XH, Wang P, Wu F, et al. BTB/POZ domain-containing protein 7: epithelialmesenchymal transition promoter and prognostic biomarker of hepatocellular carcinoma. Hepatology. 2013;57(6):2326-37.

38. Inui Y, Higashiyama S, Kawata S, Tamura S, Miyagawa J, Taniguchi N, Matsuzawa Y. Expression of heparin-binding epidermal growth factor in human hepatocellular carcinoma. Gastroenterology. 1994;107(6):1799-804.

39. Klingenberg M, Matsuda A, Diederichs S, Patel T. Non-coding RNA in hepatocellular carcinoma: mechanisms, biomarkers and therapeutic targets. J Hepatol. 2017:67(3):603-18.

40. Yang C, Zheng J, Xue Y, Yu H, Liu X, Ma J, Liu L, Wang P, Li Z, Cai H, et al. The effect of MCM3AP-AS1/miR-211/KLF5/AGGF1 Axis regulating glioblastoma angiogenesis. Front Mol Neurosci. 2017;10:437.

41. Zhao Y, Li F, Zhang X, Liu A, Qi J, Cui H, Zhao P. MicroRNA-194 acts as a prognostic marker and inhibits proliferation in hepatocellular carcinoma by targeting MAP4K4. Int J Clin Exp Pathol. 2015;8(10):12446-54.

42. Kong $Q$, Zhang S, Liang C, Zhang Y, Chen S, Qin J, Jin Y. LncRNA XIST functions as a molecular sponge of miR-194-5p to regulate MAPK1 expression in hepatocellular carcinoma cell. J Cell Biochem. 2018;119(6): $4458-68$.

43. Zhu X, Li D, Yu F, Jia C, Xie J, Ma Y, Fan S, Cai H, Luo Q, Lv Z, et al. miR-194 inhibits the proliferation, invasion, migration, and enhances the chemosensitivity of non-small cell lung cancer cells by targeting forkhead box A1 protein. Oncotarget. 2016;7(11):13139-52.

Ready to submit your research? Choose BMC and benefit from:

- fast, convenient online submission

- thorough peer review by experienced researchers in your field

- rapid publication on acceptance

- support for research data, including large and complex data types

- gold Open Access which fosters wider collaboration and increased citations

- maximum visibility for your research: over $100 \mathrm{M}$ website views per year

At $\mathrm{BMC}$, research is always in progress.

Learn more biomedcentral.com/submissions 